\title{
Research on the Electronic Commerce Application based on Services
}

\author{
Yi Dan \\ Jiangxi College Of Foreign Studies
}

\begin{abstract}
E-commerce is the inevitable choice of enterprise development in network era. Although the infrastructure, IT professionals and capital are relatively lack and the management also has different characteristics, the small and medium-sized enterprises still in an urgent need to blend in the tide of network economy, by Internet, to get the business opportunity and decision-making reference, release business, promotion and advertising information, to implement pre-market sale of after-sales service, customer follow-up research and market research, and to realize online transactions and the enterprise supply chain. From the specific requirements of enterprises, this paper fully analyzes and standardizes enterprise's current business process, and finally programs and realized guided by the paper and through system analysis and system design.
\end{abstract}

KeyWords-Computer application; Electronic commerce; $B / S$; SEAIF

\section{INTRODUCTION}

Along with the rapid development of Internet, online business activities are becoming more common. The great success of E-commerce depends largely on the enterprise information system which cannot seen by Web users. The electronic commerce is supported by a huge support system, which is composed by applications written by different computer languages and runs on different operating systems. They have different storage formats and transmission mechanisms, and support different technical standards. The integration of application must adopt a flexible and extensible mark language (XML).

At the same time, there are few domestic application software developers which can provide enterprises with the overall solution from ERP, CRM, SCR to e-commerce sites. Due to localized advantages, the domestic application software developers often have a great advantage in one kind of application software development. Whether can integrate the local advantages of each software developer as the whole advantage is directly related to the future development of domestic e-commerce. Therefore, it is urgently needed a technical framework which can easily integrate different e-commerce software.

So this paper is integrated in WEB platform based on $\mathrm{B} / \mathrm{S}$ mode enterprise management system and e-commerce system, and tightly integrated based on original data -enterprise center database platform sharing. Application integration system makes internal and external information flow directly intersect and integrate which makes the information flow among customers, internal enterprises and suppliers be smooth and connects customers, enterprises and suppliers together. It also responses the market with the fastest speed and the lowest cost, timely grasps opportunities and constantly improves and consolidates competitive advantages. This paper also studies the design and realization of enterprise center database, the enterprise management system, the solutions of e-commerce system and the system and structure of its integration and application integration system.

\section{APPLICATION NETWORK PLATFORM}

The backbone switch of application network platform has middle high end network switch with three layers switching functions, which is connected with campus network through the optical fiber module and is connected with server with $1000 \mathrm{M}$ in Ethernet. Minicomputers connect to the two PC through IXA card, which can make full use of SMARTSUN function of IBMAS / 400 .

The structure of the application network layers is shown in Fig. 1. 


\begin{tabular}{l} 
Application: The electronic government affairs, \\
The electronic commerce, The business \\
management, ERP, CRM, etc. \\
\hline $\begin{array}{l}\text { Application intermediate platform: WebSphere, } \\
\text { WebServer, Domino, etc. }\end{array}$ \\
\hline Database: Oracle, Sybase, DB2, SQLserver \\
\hline Network operating system: WNIX, \\
Windows2000, OS/400 \\
\hline Network server: PC server, minicomputer \\
\hline
\end{tabular}

Figure .1 The layers of the application network platform

\section{E-COMMERCE PLATFORM}

With the continuous development of electronic commerce and electronic government affairs, to understand and master the application environment of electronic commerce and electronic government affairs is the indispensable basic knowledge and skills for computer and related professional students. As the most mature and practical e-commerce platform software, Websphere has become one of the indispensable platform software to implement electronic commerce and electronic government affairs. Websphere Apphcation Server provides rich e-commerce application deployment environment with a complete set of application services, including transaction management, security, clustering, performance, availability, connectivity and scalability functions. It is a Web application server based on Java, which can help to deploy and manage many applications from simply Web site to power e-business solutions.

Internet-based e-commerce runs as shown in Fig .2:

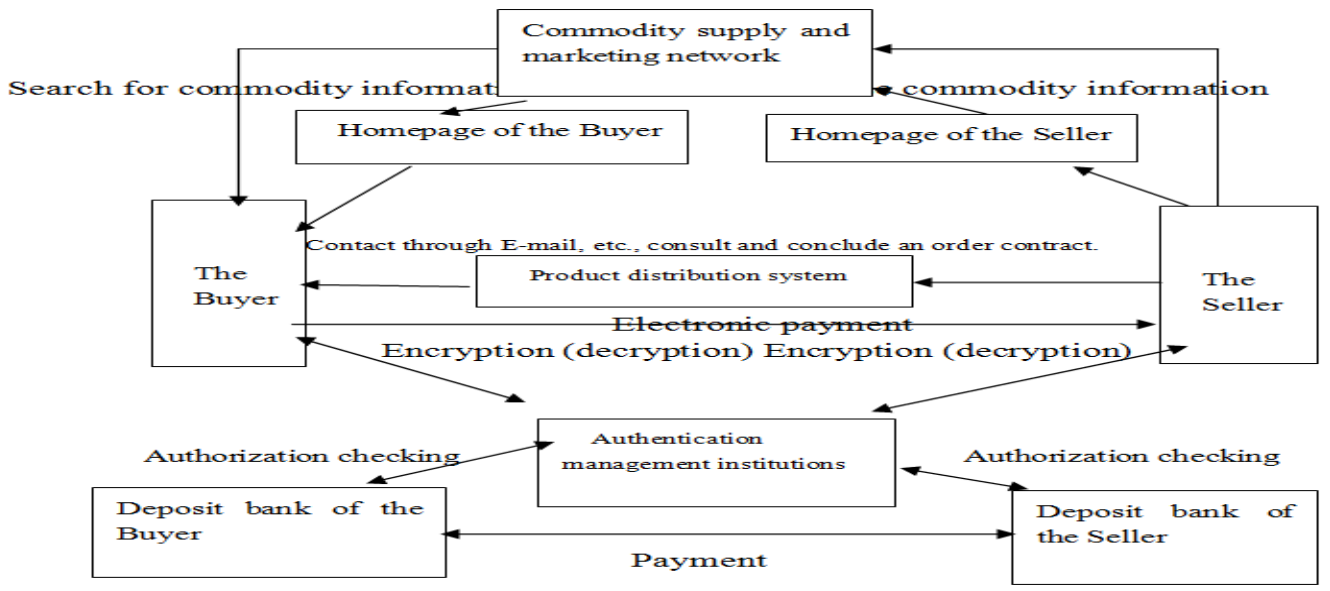

Internet-based e-commerce operation mode

Generally speaking, e-commerce can be mainly divided into the following two modes, business to end custom, which is known as $\mathrm{B} 2 \mathrm{C}$ and business to business, which is known as B2B.

\section{SEAIF SYSTEM STRUCTURE}

SEAIF system structure. The structure divides the services into three layers: Web service, enterprise application service and application component service. According to the three service layers, there are three domains: Web domain, enterprise computing environment domain and application component domain. Web services are completed through enterprise application service and enterprise application service is completed through application component service.

SEAIF shows the dependencies between services to levels of service and service level. Application component service is Level 1, enterprise application service is Level 2 and Web services is Level 3. Web services is the highest level of service, component service is the lowest service. High level services rely on low level service. Also, in the same domain, services are further divided into several 
levels. Figure 3 is an instance of the service levels. The different levels of service constitute mesh structure. The arrow from Service a to Service $b$ indicates that Service a

$$
\zeta\left(a^{\prime}\right)=\max (\zeta(a), \zeta(b), \cdots, \zeta(k))+1
$$

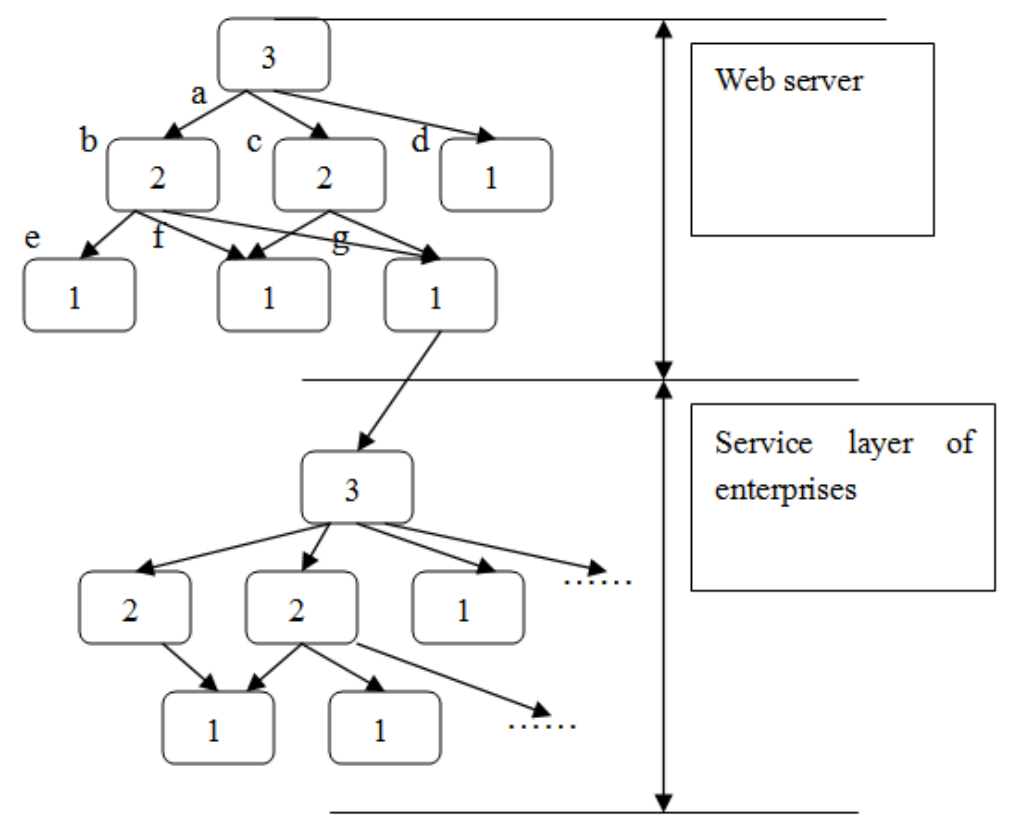

Figure 3. SEAFI service layer

Taking Web layer service in Fig. 3 as an example, explain the computing level of SEAIF computing, Web domain service dependencies expression is as follows:

$$
\begin{aligned}
& a=\theta(b, c, d), \quad, \quad b=\theta(e, f, g), \\
& c=\theta(f, g)
\end{aligned}
$$$$
\text { it can be obtained from Formula (1), that }
$$$$
\begin{aligned}
& \zeta(b)=\max (\zeta(e), \zeta(f), \zeta(g))+1=\max (1,1,1) \\
& \zeta(c)=\max (\zeta(f), \zeta(g))+1=2
\end{aligned}
$$

so,

$$
\left.\zeta(a)=\max (\zeta(b) \zeta \phi))_{s} d\right)+1=3
$$

Conclusion

Network era has arrived and any state, enterprise or individual should not refuse it, or they will lag behind the social development. Although there are a variety of problems, we cannot blindly be on the sidelines or wait until all the problems are solved then to participate in, depends on Service b. The service level calculation formula is: 
based on a central database integration and provides integration framework for enterprise application extension which is easy to extend.

\section{REFERENCE}

[1] Macdonald, I. D. (1974). A computer application to finite p-groups. Journal of the Australian Mathematical Society, 17(1), 102-112.

[2] Shi, Jiaoying, and Z. Pan. "China: computer graphics is fastest developing computer application." Acm Siggraph Computer Graphics (1996):11-14.

[3] Kressig, Reto W,, and K. V. Echt. "Exercise Prescribing: Computer Application in Older Adults." Gerontologist 42.2(2002):273-277.

[4] Vinoski, S. (2003). It's just a mapping problem [computer application adaptation]. IEEE Internet Computing, 7(3), 88-90.

[5] Card, S. K., and D. A. Henderson. "CATAloguES: A METAPHOR FOR COMPUTER APPLICATION DELIVERY." Human-computer Interaction-interact (1987):959-964.

[6] Smith, C. E., A. C. Roth, and S. M. Milner. "Palm-Top Computer
Application for Fluid Resuscitation in Burns: 269..." Journal of Burn Care \& Research 22(2001)

[7] Card S K, Henderson D A. CATALOGUES: A METAPHOR FOR COMPUTER APPLICATION DELIVERY[J]. Human-computer Interaction-interact, 1987:959-964.

[8] Neumann, D. (1986). A psychotherapeutic computer application: modification of technological competence. Behavior Research Methods, 18(2), 135-140.

[9] Kennedy, T., and A. G. Hoffmann. "On-Line Digital Computer Application Techniques for Complex Electric System Dispatch." Power Apparatus \& Systems IEEE Transactions on pas-87.1(1968):67 - 73.

[10] Zeng, Rong. "Essay Talk of Information Management of Computer Application Laboratory." Computer Programming Skills \& Maintenance (2012).

[11] Zeng, Rong. "Essay Talk of Information Management of Computer Application Laboratory." Computer Programming Skills \& Maintenance (2012)

[12] Liao, R. H., Ying, H. U., Yong-Fan, L. I., \& Wen, H. Y. (2009). College computer application test system based on b/s and c/s. Journal of Hunan First Normal University. 